\title{
Welcome to the new Journal of Cloud Computing by Springer
}

\author{
Chunming Rong ${ }^{{ }^{*}}$ and Zhiming Zhao ${ }^{2}$
}

Since 2012, the Journal of Cloud Computing has been promoting research and technology development related to Cloud Computing, as an elastic framework for provisioning complex infrastructure services on-demand, including service models such as Infrastructure as a Service (IaaS), Platform as a Service (PaaS), and Software as a Service (SaaS). The industry has been driving the Cloud development at an ever rapid pace, especially recently in relation to industrial automation, artificial intelligence, blockchain and Cloud-Edge-IoT convergence as well as 5G and Next Generation Internet. There are efforts in improving and facilitating modern scientific research, supporting high-tech industry, and creating a more effective general collaborative environment for different human activities. There is a vital need to involve more academic research on Cloud Computing technologies.

The journal shall become the gathering place for academic researchers, practitioners and business innovators alike, where they may publish their work together to embrace, promote and enhance cloud computing technologies and their applications.

Leading the new editorial team, the Editor-in-Chief (EiC) Prof. Chunming Rong has served extensively in leadership of IEEE Cloud Computing communities and led the transition to the IEEE CS Technical Committee on Cloud Computing (TCCLD). He served as the steering chair (2016-2019), steering member and associate editor of the IEEE Transactions on Cloud Computing (TCC) since 2016. Prof. Rong has extensive experience in managing large-scale research and innovation projects, both in Norway and the EU.

Furthermore, the review workflow is operationally handled by the Managing Editor-in-Chief Dr. Zhiming Zhao, who is an active researcher in the area of cloud computing, distributed systems, and blockchain. Since 2015, he has led the research and development efforts related to cloud automation, advanced cloud service model, and cloud data management in several EU H2020 projects, including SWITCH, ARTICONF, ENVR Iplus and ENVRI-FAIR.

Together with the new editorial teams, led by topic chairs in Advanced Cloud Service, Cloud-Edge-IoT, Cloud Network, Security, Datacenter Infrastructure, and Applications.

Our goal is to promote the journal to reach board recognition and higher impact factors.

We welcome your articles as well as proposals of special issues related to emerging topics involving at least one of our associate editors.

Prof. Chunming Rong (Editor-in-Chief)

Dr. Zhiming Zhao (Managing Editor-in-Chief)

Authors' contributions

The authors read and approved the final manuscript.

Competing interests

The authors declare that they have no competing interests.

Author details

${ }^{1}$ University of Stavanger, Stavanger, Norway. ${ }^{2}$ University of Amsterdam, Amsterdam, The Netherlands.

Published online: 10 September 2021

\section{Publisher's Note}

Springer Nature remains neutral with regard to jurisdictional claims in published maps and institutional affiliations.

* Correspondence: chunming.rong@uis.no

${ }^{1}$ University of Stavanger, Stavanger, Norway

Full list of author information is available at the end of the article

(C) The Author(s). 2021 Open Access This article is licensed under a Creative Commons Attribution 4.0 International License, which permits use, sharing, adaptation, distribution and reproduction in any medium or format, as long as you give appropriate credit to the original author(s) and the source, provide a link to the Creative Commons licence, and indicate if changes were made. The images or other third party material in this article are included in the article's Creative Commons licence, unless indicated otherwise in a credit line to the material. If material is not included in the article's Creative Commons licence and your intended use is not permitted by statutory regulation or exceeds the permitted use, you will need to obtain permission directly from the copyright holder. To view a copy of this licence, visit http://creativecommons.org/licenses/by/4.0/. 